\title{
Hierofonía y cosmología en el arte indígena del Valle de Sibundoy ${ }^{1}$
}

\author{
Oscar Fernando Sánchez Suárez² \\ Corporación Universitaria Minuto de Dios - Bogotá, Colombia \\ osanchez@uniminuto.edu, oskarfss@gmail.com
}

1 Artículo de reflexión

2 Maestro en Artes Plásticas, Artes visuales, Diseño y Fotografía. UNIMINUTO, Facultad de educación. Docente-Investigador en el área de pedagogía artística. 


\title{
Hierofonía y cosmología en el arte indígena del Valle de Sibundoy
}

\section{Resumen}

Con este artículo queremos presentar un análisis de la gran diversidad cultural indígena existente en el continente sudamericano, como parte inicial del estudio y soporte de la investigación. También es una reflexión desde la mirada de diferentes autores sobre el pensamiento del hombre, en relación con su naturaleza, arquetipos, cosmogonía y ritos, y como este se teje con la historia de los pueblos o etnias kamentzá e inga. Comunidades habitantes del Valle de Sibundoy en el departamento de Putumayo, Colombia. Desde este horizonte queremos hacer visible la influencia marcada de las culturas amerindias y orientales, y como han tenido gran relevancia e importancia en las demás culturas del continente. De igual manera, observamos la naturaleza del arte indígena y su estética como parte importante en el desarrollo de la cosmología y espiritualidad, plasmadas en los diferentes objetos y elementos estéticos propios de la cultura kamentzá e inga.

Palabras clave: Hierofonía, pensamiento, cosmología, arte indígena, territorio, iconografía, mito, rito.

\section{Hierofonía and cosmology in indigenous art Sibundoy Valley}

\begin{abstract}
An analysis of the large existing indigenous cultural diversity in South America as the initial part of the study and support of research is presented. It is also a reflection from the perspective of different authors on the thinking of man in relation to nature, archetypes, cosmogony and rituals. It is also woven with the history of the peoples or ethnic communities of Kamentzá and Inga. The inhabitants of Sibundoy Valley, Putumayo Colombia show a strong influence of Eastern and other Amerindian cultures that have had a great relevance and importance on other cultures of the continent. Similarly, it treats the nature of the Indian art and aesthetics as an important aspect in the development of cosmology and the spirituality embodied in the different objects and in the aesthetics in other elements of cultural elements proper to the Kamentzá and Inga cultures.
\end{abstract}

Keywords: Hierofonía, Thought, Cosmology, Indigenous Art, Territory, Iconography, Myth, Rite.

\section{Hierofania e cosmologia no arte indigena da Planície de Sibundoy}

\section{Resumo}

Apresenta-se uma análise da grande diversidade cultural indígena do continente da América do Sul, como parte inicial do estudo e base da pesquisa. Assim mesmo, é uma reflexão desde a perspectiva de diferentes autores sobre o pensamento do humano, na relação com a natureza, arquétipos, cosmogonia e ritos dele. Além disso, a análise é relacionada com a história dos povos ou etnias Kamentzá e Inga, que habitam a planície de Sibundoy, no estado Putumayo, Colômbia. Desta maneira, é mostrada a influência de outras culturas ameríndias e orientais, e como essas culturas têm tido uma grande relevância e importância nas outras culturas do continente. Assim mesmo, é estudada a natureza da arte indígena e sua estética como parte importante do desenvolvimento da cosmologia e a espiritualidade, refletidos nos diferentes objetos e elementos estéticos próprios das culturas Kamentzá e Inga.

Palavras chave: Hierofania, Pensamento, Cosmologia, Arte Indígena, Território, Iconografia, Mito, Rito. 


\title{
Introducción
}

\begin{abstract}
Si tenemos en cuenta la inserción del hombre en la naturaleza, las verdades humanas se convierten en verdades de la naturaleza. Ilya Prigogine
\end{abstract}

América del sur, un inmenso continente de arte, cultura y tradiciones ancestrales desde tiempos inmemorables. El hombre primitivo prospera en una fina simbiosis, entre lo mágico de su espiritualidad y lo cósmico de su medio ambiente, su naturaleza, es la conexión de su destino religioso con las fuerzas del universo, en cuyo caso, acorde con la máxima de santo Tomás, "la gracia perfecciona la naturaleza". Y es precisamente la gracia de su arte y pensamiento, la que le permite surcar los tiempos del hombre, en su historia, para engrandecer su espíritu creador. Esta cultura suramericana es enormemente compleja, rica y variada en recursos naturales, y con un conocimiento propio y particular de su medio natural. Las tribus o pueblos indígenas se mantuvieron intactos, hasta la aparición del hombre blanco occidental, que con su admitida civilización, arrasó con toda creencia, costumbre y tradición. Pero gracias al talante y al ethos que poseía el hombre prehispánico, sus futuras generaciones se amarran en el presente por tratar de salvaguardar su legado más preciado, sus tradiciones. Es indiscutible, que las civilizaciones mesoamericana y andina, prosperan al margen de Europa y Oriente, y que su desconocimiento del metal las vuelve vulnerables a estos pueblos. El uso de la cerámica, la piedra, la madera y la pintura, son utilizados para reafirmar sus visiones y su forma particular de ver el mundo al detalle. Estas culturas se dividen en tres periodos cronológicos: período preclásico, desde 2500 a. C. hasta el año 200 d.C.; periodo clásico, del 200 d. C. al 800 d.C.; y Período Posclásico, del 800 hasta la conquista española 1521, aproximadamente.

Los pueblos Prehispánicos o Precolombinos son todos aquellos que habitaban en el continente antes de la llegada de los colonizadores españoles. Algunas de las culturas, para ese momento, eran aún muy primitivas, pero otras estaban bastante desarrolladas y eran muy civilizadas, como era el caso de los mayas, los incas y los aztecas. El área mesoamericana está conformada por México, Guatemala, Belice, El Salvador, Honduras y parte de Nicaragua, en todos estos países existían muchas manifestaciones culturales muy similares: variedad de pirámides, juego de pelota, patios cubiertos con escayola, meses de veinte días, calendario solar, sistema numérico vigesimal, cultivo de cacao y maguey con el que fabricaban papel, y el peyote planta sagrada, la que utilizan como puente espiritual, para conectarse con el universo y con sus ancestros de nobles linajes, antiguos y solariegos. La siguiente área circun-caribe, Colombia y Venezuela, con tribus como chibchas, caribes, arauacos, koguis, y otros. Y por último, 
el área andina conformada por el resto de los países latinoamericanos, y sus tribus más destacadas como: tupis, karas, quechuas, mojos, aymaras, guaranies, araucanos y patagones, entre otros. Es de resaltar el imperio incaico que se formó entre siglo XIV y XV en todo el continente suramericano. Qhapag Ñan o camino del rey, un sistema de camino que recorre $5200 \mathrm{Km}$ entre Quito Ecuador, y Tucumán, la provincia más pequeña y una de las más antiguas de Argentina.

Suramérica continental tiene casi 18.000.000 de kilómetros cuadrados, entre los $12^{\circ}$ de latitud norte y $55^{\circ}$ de latitud sur. La mayor parte de su territorio se encuentra en una latitud tropical, pero debido a unas circunstancias fisiográficas muy particulares, se da una gran variedad climática y ambiental. La colosal cordillera andina, espina dorsal del continente, recorre una extensión de $7500 \mathrm{~km}$ de longitud, y alturas de casi los 7000m que abarcan las nieves perpetuas hasta las verdes selvas tropicales, hogar de una gran variedad de etnias y aborígenes. Según el Fondo Internacional de Desarrollo Agrícola, FIDA, y organismo especializado de las Naciones Unidas: "En el mundo hay más de 370 millones de personas que se definen a sí mismas como indígenas, las cuales están distribuidas en unos 70 países. Solo en América Latina hay más de 400 grupos, cada uno con su propia lengua y cultura" (FIDA, 2012).

Pareciera ser que el sur del área circun-caribe, con su gran territorio amazónico, separó en algún momento Mesoamérica del área andina. Esta enorme y mágica región del mundo posee un lenguaje espiritual y cosmológico muy específico. Según Rumrill en su escrito Amazónica Mágica: "Para el pensamiento mágico amazónico existe un único cosmos compuesto por diversos mundos: el bosque, los ríos, las cochas [...]" (Rumrill, 2008), porque el acto de la manifestación de lo sagrado, llamado también hierofonía, radica en el conocimiento y reflexión que se tiene del medio ambiente. Es aquí donde nace una nueva raza, los indígenas del Valle de Sibundoy, su toponimia o nombre original de la región, es Tabanoy, que traduce pueblo grande, su territorio fue ocupado en 1535 por Juan de Ampudia.

Los habitantes más antiguos del valle son los indígenas inga y kámsa o kamentzá. Un pueblo que por estar tan cerca del sistema Qhapag Ñan, posee una de las manifestaciones rupestres más antiguas de Colombia. Cada material lítico disperso por el territorio, parece cobrar vida en las historias contadas por los taitas del valle de Sibundoy. Pachamama emerge con sus leyes naturales y es interpretada a partir de los diseños, dibujos, tallas, alfarería, y por supuesto a través de las ceremonias que se realizan con la planta sagrada del Yagé. Eliade nos dice que, "el valor mágico y farmacéutico de ciertas hierbas se debe también a un prototipo celeste de la planta o al hecho de que ésta fue cogida por primera vez por un dios: "Las etnias del piedemonte Amazónico, Kamentzá e Inga, nos enseñan que no somos dueños de la madre tierra, que pertenecemos a ella. Cada trazo en sus decorados nos habla de reconstruir nuestra espiritualidad, nuestra vida cósmica-telúrica, y que las ofrendas y oraciones son parte esencial de lo cotidiano" (Eliade, 1995). 


\section{Sistema y ubicación geográfica}

El Valle de Sibundoy, pertenece al alto Putumayo, es un bosque andino de niebla ubicado a 2100 m.s.n.m, situado al extremo noroccidental en la intendencia del Putumayo. Esta zona hace parte de la cordillera de los andes y limita al sureste con la cordillera de Portachuelo y Patascoy, al noreste con los cerros de Bordoncillo, Campanero, y Cascabel. Cuenta con el nacimiento de varios ríos, de gran importancia y trascendencia cultural para sus habitantes, como lo son el rio San Pedro, el rio Putumayo, y el rio San Francisco. Territorio quebrado, el cual pertenece a la vertiente oriental de la cordillera de los Andes, clima frio con alturas inferiores a los $3000 \mathrm{~m}$, lo cual permite el manejo micro-vertical de los recursos, es decir que en cada piso térmico hay enclaves especializados que se dedican a la explotación de los recursos disponibles. Este sistema de terrazas es el que ha permitido que la región del alto y bajo Sibundoy se haya especializado en el manejo de su patrimonio natural. A éste pertenecen los municipios de San Andrés, Santiago, Colón, Sibundoy, San Pedro, y San Francisco. Estos pueblos están arraigados en la parte alta del valle, mientras que los grupos indígenas se encuentran más abajo y hacia el centro del valle.

\section{Estilo, forma y color en la espiritualidad indígena}

Estos grupos indígenas son descendientes directos de los incas de los Mitimaes del Tawan-tisuiu, los cuales trajeron al alto y bajo Putumayo, una forma de vida y de pensamiento, lenguaje y cultura, estrechamente relacionada con la cosmología. Ellos sabían, que toda forma de vida es el resultado de la aplicación de un sistema, conformado por unos principios y leyes que provienen de la misma naturaleza, de la Pachamama. Es probable, que los grupos quechua y aymara, en busca de nuevas tierras se hayan adentrado en selvas Colombianas y formando grupos de avanzada militar, para repeler la invasión española en el siglo XV, y que sus tradiciones ancestrales en cuanto a la cultura y el arte, se transfieran de generación en generación. De ahí, el nacimiento de tribus como los siona y coreguaje, localizados al sur-este de Putumayo, y que se caracterizan por ser grupos indígenas aguerridos y temerarios.

Las tradiciones y ceremonias sagradas que comparten Nariño y Putumayo vienen de un conocimiento y saber ancestral. El festival de blancos y negros de Pasto y el festival indígena en el Valle de Sibundoy muestran tres ejes temáticos: patrimonio, biodiversidad, y saberes ancestrales. Integrados por unos ejes de cultura de convivencia y ceremonias sagradas, donde solo pueden participar integrantes de la misma comunidad indígena. El "surco de saberes" es un momento para las charlas y conferencias ostentosas de conocimiento. El "jardín de las palabras" reservado para los taitas, curacas o mamas, poseedores del saber ancestral. Todo un carnaval para celebrar la vida y la unión de un pueblo con sus ancestros.

El diseño de sus artesanías y su arte hablan de historias de taitas, de mitos y ritos, de encuentros con los personajes mágicos de la selva, del bosque, del universo. 
Cada forma es una explosión de color, es una "pinta", un fosfeno y un signo, que da sentido a su existencia. Según Duncan (1992) "El subsistema de signos mencionado por Eco, es interpretado aquí como un repertorio de formas culturales que un grupo específico podría usar, de acuerdo con sus necesidades e intereses, para crear composiciones visuales" Estos diseños o sistemas son elaborados a partir de formas geométricas, con niveles de abstracción y realidad, que reflejan o manifiestan una narrativa de forma axial. Es decir que los puntos de una figura geométrica deben coincidir con los de otra, para formar una rotación radial, en donde varias figuras puedan participar de un carácter o diseño particular como en la siguiente figura.
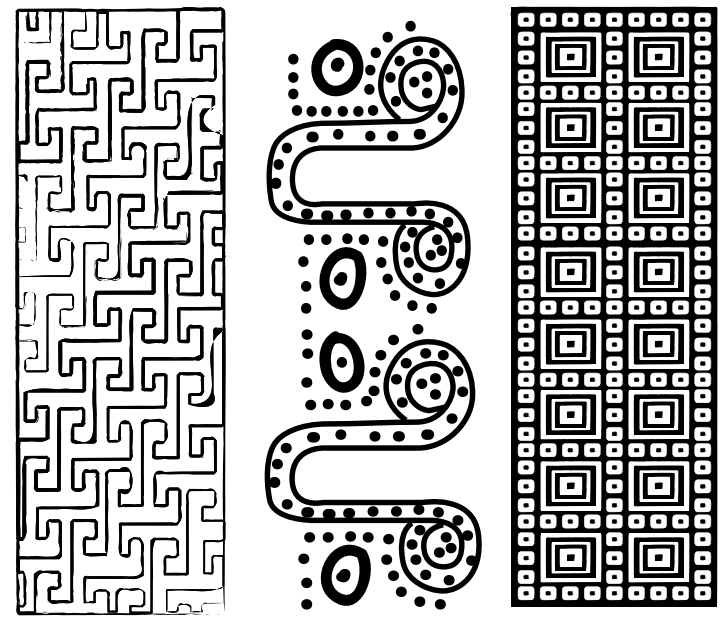

FIGURA 1. Fuente: Luz Helena Ballestas (2007). La serpiente en el diseño indígena colombiano.

Por otro lado la iconografía rupestre, está representada por una serie de piedras también conocidas como "piedras de antigua", las cuales se asocian a sagrados rituales. Según la doctora Flórez, antropóloga e investigadora de la universidad de Antioquia "[...] logramos la ubicación y el registro de cincuenta piedras talladas: veintiocho piedras con petroglifos, cinco de ellas con oquedades, veintiún piedras sólo con oquedades y una lito-escultura" (Flórez, 2008). Ésto indica una función social y cultural muy marcada en relación con este arte lítico y su relación con la vida diaria de los habitantes del valle, las piedras "vivas" como las llaman, han transcendido su forma para albergar otros significados. Asunto que se puede entender mejor en el libro de Eliade, El mito del eterno retorno: "[...] una roca se muestra como sagrada porque su propia existencia es una hierofonía: incomprensible, invulnerable, es lo que el hombre no es. Su realidad se ve duplicada por la perennidad" (Eliade, 1995). La gran mayoría de las piedras se ubican en laderas y cerca de las fuentes de agua, 
esto corresponde a las terrazas y andenes de cultivos prehispánicos, que estudia y describe Patiño (1995).

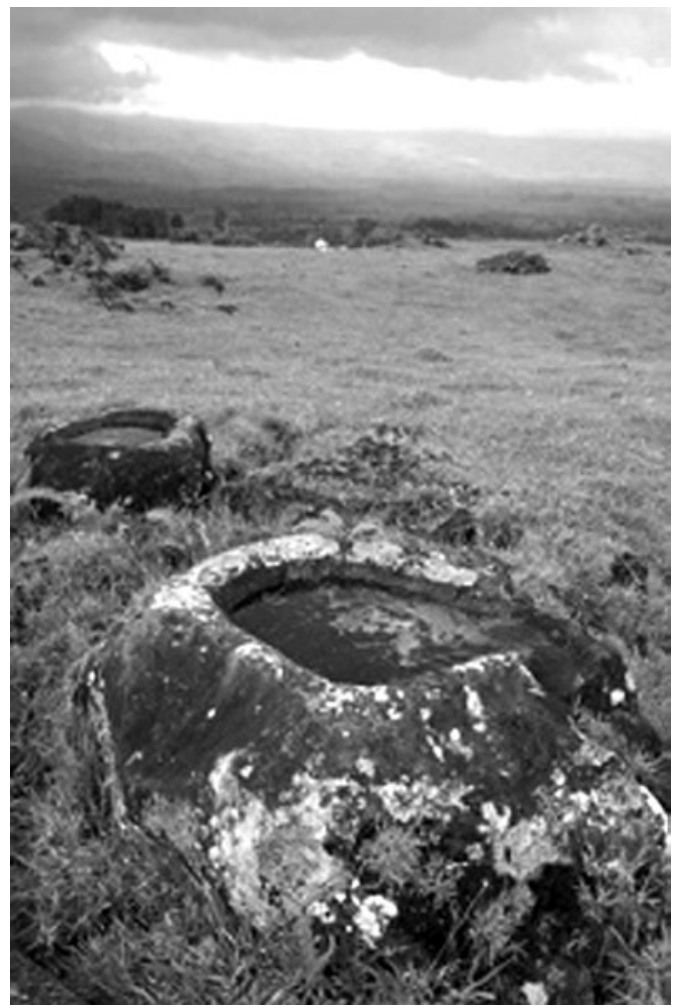

FIGURA 2. Piedras con oquedades. Municipio de Santiago, Valle de Sibundoy. Fuente: Luz Helena Ballestas (2007).

Podríamos decir que el arte del valle, surge del éxtasis de sus rituales. De su relación con los animales sagrados de la selva, como el tigre o jaguar amazónico, y la serpiente o boa. Y de su particularidad de relacionarse con los demás habitantes del planeta como lo documenta Chaves y Vieco: "Los indígenas del alto CaquetáPutumayo son los que se hallan más integrados a la sociedad nacional, de todos los indígenas de la Amazonia, debido a que ésta es la zona de colonización más importante y dinámica de la Amazonia colombiana" (Chaves y Vieco, 2008).

El arte de Sibundoy es muy particular, podemos distinguir unas representaciones generales como: esferas de luz, relámpagos y cuerpos celestes que hacen parte de sus diseños cosmológicos inscritos en sus artesanías. Un atributo especial se centra en la cabeza, lugar donde reside el poder. Son las coronas, diademas y máscaras. La condición de poderío expresado en sus bastones, báculos y tocados. La influencia 
sobre la naturaleza, referida mediante la contención en sus manos de serpientes, boas, jaguares y otros animales de poder. El proceso de transformación se expresa mediante figuras zoomorfas, que muestran el tránsito de la muerte a la vida, y de vida a la muerte. El banco o taburete, que representa el poder del pensamiento, donde el taita se sienta a pensar "bonito", para ayudar al paso de este mundo, al mundo de los espíritus. Las máscaras en el mundo inga y kamentzá tienen un trasfondo cosmológico, que encarnan dioses y demonios, que suelen intervenir en danzas y festividades. Las máscaras se relacionan con los mitos, con rituales de iniciación y con un nuevo estatus o título. El oficio artesanal es una expresión muy marcada que muestra su relación con el universo y con la naturaleza. Es una comunión expresada desde el interior de cada habitante del valle: es un camino. Como decía el poeta alemán Novalis: "El camino misterioso va hacia el interior. Es en nosotros, y no en otra parte, donde se halla la eternidad de los mundos, el pasado y el futuro" (Novalis, 2006).

\section{Población y pensamiento hierático y ancestral}

La interesante historia del origen de la palabra hierática, nos refiere a varias acepciones, una es la falta de expresividad que se puede apreciar en algunas pinturas y esculturas clásicas. Se aplica también a la persona que permanece seria e inexpresiva. Se aplica a la escritura egipcia que era una simplificación de la jeroglífica. En este ensayo me refiero por hierático a lo sagrado, solemne y religioso de los poblados ancestrales que se mantienen en el Valle de Sibundoy.

Existe un corredor milenario y dinámico entre la región andina y la región amazónica, donde habitan diferentes grupos étnicos, y que gracias a permanecer relativamente aislada durante muchos siglos, pudieron mantener un proceso de reconstrucción poblacional que permitió la subsistencia de su cultura y tradiciones.

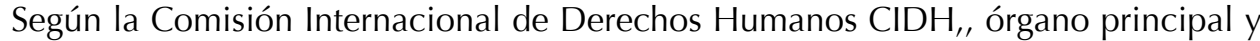
autónomo de la Organización de los Estados Americanos (OEA): "[...] el Derecho a la propiedad bajo el artículo 21 de la convención Americana sobre derechos humanos tiene, por ende, una importancia singular para los pueblos indígenas y tribales, porque la garantía del derecho a la propiedad territorial es una base fundamental para el desarrollo de la cultura, la vida espiritual, la integridad y la supervivencia económica de las comunidades indígenas" (CIDH, 2011). Esto, en la realidad, es un asunto que hay que ver con sumo cuidado, pues se violentan estos derechos con mucha facilidad por parte del estado, los grupos al margen de la ley y la influencia de las grandes ciudades en las culturas indígenas, marca una posible dispersión entre los habitantes de territorios nativos.

El nacimiento de "pueblo" surge cuando el hombre deja de vagar por las planicies y su principal objetivo es conocer los secretos que tiene la madre tierra, en otras palabras, la caverna se abandona, y después de ambular por diferentes territorios, el hombre toma la decisión de establecerse, y es cuando se ejecutan las 
primitivas formas arquitectónicas en el periodo prehistórico de la humanidad. En esta época surgen los primeros monumentos y las concepciones mentales cambian con el dominio y manejo técnico de la piedra. Pero esto va más allá según explica Eliade: "En particular, el templo — lugar sagrado por excelencia - tiene un prototipo celeste" (Eliade, 2009, 17).

Es decir, que del tiempo de contemplación que surge en los primitivos hombres primitivos, nace un arquetipo que permite modelar el pensamiento. Para Eliade: "El más antiguo referente al arquetipo de un santuario, es la inscripción de Gudea relacionada con el templo levantado por él en Lagash" (Eliade, 2009, 17). Para Jung en su libro Realidad del alma, propone que: "[...] en el mundo primitivo todos los hombres poseían una especie de alma colectiva, pero con el pasar de los años y la evolución, surgió un pensamiento y una conciencia individual que ayudó en gran parte con la formación del modo de pensar de cada cultura y de su tipo de actuar" (Jung, 2003).

Para Platón "[...] el arquetipo expresa las formas sustanciales — ejemplares eternos y perfectos - de las cosas que existen eternamente en el pensamiento divino [...]" (Platón, 1969). En cuanto a las civilizaciones primitivas indígenas colombianas, el arquetipo, al igual que para otras culturas, está regido por tres ámbitos: conocimiento, poder y amor. El primero, estrechamente relacionado con el pensamiento, que no lo presento ni lo expongo, como la actividad exclusiva de la razón, o que ésta se entrelace con la racionalidad, que vendría siendo un concepto saturado de ambigüedad y mistificado por una práctica occidental. Tampoco ahondar en su contenido semántico. En el caso de las tradiciones indígenas, el pensamiento, es el conocimiento y convivencia con la naturaleza, que les otorga renovación y vida. El conocimiento se puede entender mejor si se identifica a Qhapag Ñan, como la escuela de sabiduría andina. En él se develan los principios filosóficos y espirituales del pensamiento indígena, que nos muestra Lajos (2005) en su libro Qhapag Ñan la ruta inca de sabiduría. El segundo ámbito, el poder. Estrechamente relacionada con el respeto por los sueños. En lo onírico se entreteje lo terrenal y lo cosmogónico, para dar paso al conocimiento.

El conocimiento proporciona el temple que se requiere para adquirir el poder de la madre naturaleza, es decir, que si se tiene conocimiento de las plantas y habitantes de la selva, se tendrá el poder de vivir en comunidad ayudando a los demás. Pero para acceder al poder hay que ser un guerrero humilde, Castaneda en su libro, Relatos de poder, nos dice que: "[...] se acepta con humildad así como es, no como base para lamentarse, sino como base para su lucha y su desafío" (Castaneda, 2000). Un guerrero indígena, en el caso de los kamentzá e inga, se capacita en la comprensión y sabiduría que les otorga las plantas de poder. La cosmovisión chamánica, en cuanto al manejo de la planta sagrada del yagé, en el Valle de Sibundoy, está orientada por los Siona que conceden su conocimiento a sus hermanos del valle. 
El yagé, les permite visualizar y concentrar el pensamiento sobre la selva, para dar solución a enfermedades que se llegue a tener y poder curarlas. Por otro lado les confiere voluntad de conocimiento para comprender las representaciones sensoriales inexpresables que se presentan durante una ceremonia o rito del yagé. El último ámbito, amor, virtud que poseen la mayoría de los indígenas colombianos, sentimiento que está enmarcado en una visión de conciencia, que pretende reestablecer los vínculos rotos de sociedad, naturaleza, hombre, mujer, tierra y universo.

\section{Conclusiones}

Las colectividades indígenas han estado al borde de su extinción, en parte por su poca preocupación por mantener en la actualidad sus costumbres, y por otro lado, por el abordaje indiscriminado de las sociedades modernas, que con su tecno-cultura y ansias por experimentar de una manera errónea, ritos y expresiones indígenas sagrados, descontextualizan y distorsionan lo que se debe tener como sagrado y oculto a los ojos de los demás. Como describe Herrigel en su ensayo Zen en el arte del tiro con arco: "El meramente curioso no tiene derecho... El Zen, como toda mística, será comprendido únicamente por un místico que... no sucumbirá a la tentación de obtener en forma subrepticia lo que la experiencia mística le niega" (Herrigel, 2012). En este caso el "Zen" lo podríamos corresponder con las tradiciones y culturas indígenas ancestrales, que son el camino y el horizonte para tener en cuenta. Tener en cuenta y enaltecer el misticismo que poseen todavía algunos taitas del valle de Sibundoy, manteniendo en secreto y unidad familiar, su legado más preciado: su pensamiento.

En cuanto al arte y el diseño, sigue siendo una muestra enormemente única, mágica y universal. Sus diseños son visiones telúricas, —relativo a la Pachamamay el arte parte de su pensamiento — conocimiento—, con explosiones y convulsiones de color, guiados por el espíritu de las plantas de poder.

La sociedad indígena ha cambiado y seguirá cambiando, y es menester de nosotros, sus "hermanitos menores" como dicen los kogui, respetar sus territorios, costumbres ancestrales y construir conciencia en la importancia por preservar nuestros ancestros. Las culturas indígenas son un sistema delicado e influenciable por las sórdidas luces del progreso. Aún así, se conservan y luchan por mantener a sus hijos con olor a selva, y conectados al infinito. 


\section{Referencias}

Castaneda, C. (2000) Relatos de poder. México: Editorial Fondo de Cultura Económica.

Chávez, M. y Vieco J. J. (2008). Introducción a la Colombia Amerindia, Bogotá: Editorial Instituto Colombiano de Antropología.

$\mathrm{CIDH}$. Centro de Información de Derechos Humanos. Recuperado de http://www.cidh.org. Eliade, M. (1995). El Mito del Eterno Retorno, Madrid: Alianza Editorial.

FIDA. Fondo Internacional de Desarrollo Agrícola. Recuperado de http://www.ifad.org/pub/ factsheet/ip/s.pdf

Flórez, A. L. (2008). Del pensamiento a la piedra y de la piedra al pensamiento. Piedras con dibujos en el valle de Sibundoy. "Monografía de grado no publicada", Departamento de Antropología, Universidad de Antioquia, Medellín.

Herrigel, E. Zen en el tiro con arco. Recuperado de http://textosmonasticos.files.wordpress. com/2010/01/tiroconarco.pdf

Jung, C. G. (2003). Realidad del alma. Buenos Aires: Editorial Losada.

Lajos, J. (2005). Qhapag Ñan, ruta Inka de la sabiduría. Lima: Amaru Runa Ediciones.

Novalis, H.F. (2006). Canciones espirituales. Sevilla: Editorial Renacimiento.

Patiño. D. (1995). El Altiplano Nariñense, el Valle de Sibundoy y la Ceja de Montaña Andina en el Putumayo. Cali: Imprenta Departamental Valle Del Cauca.

Platón. (1969). La república. En: Platón. Obras completas. Madrid: Aguilar.

Ramírez, M. C. (1996). Frontera fluida entre Andes, piedemonte y selva: el caso del valle de Sibundoy, siglos XVI-XVIII. Cuadernos de Historia Colonial. (4).

Rumrill, R. (2008). Amazonía Mágica. Lima: Editorial Chirapaq.

Recibido: 17 julio 2012

Aceptado: 21 septiembre 2012

Cómo citar:

Sánchez, O. (2013). Hierofonía y cosmología en el arte indígena del Valle de Sibundoy.

Praxis Pedagógica 14, 45-55 